\title{
EL DESARROLLO DE LA COMPETENCIA INTERNACIONAL. PRIMEROS APORTES DESDE NÜREMBERG Y TOKIO
}

Jaime Alberto Sandoval Mesa*

Fecha de recibido: 30 de marzo de 2012

Fecha de aprobación: 20 de junio de 2012

Artículo resultado de investigación.

\section{Resumen}

El presente artículo analiza las experiencias para la construcción de la justicia penal internacional que desde los Tribunales de Nüremberg y Tokio construyeron y adicionaron los principales factores de competencia que sirven de base en la actualidad para la realidad que se representa en la Corte Penal Internacional. A través del presente documento se pretende mostrar que antes de abordar la cuestión de admisibilidad contemporánea ante la CPI, es importante conocer como se han construido sus bases y de donde devienen sus principales instituciones.

\section{Palabras clave}

Jurisdicción internacional, Tribunales de Nüremberg y Tokio, Crímenes contra la Paz, Crímenes contra la Humanidad, Crímenes de Guerra. Responsabilidad individual, Responsabilidad del superior y Responsabilidad por la organización.

\section{THE DEVELOPMENT OF INTERNATIONAL COMPETITION. FIRST CONTRIBUTIONS SINCE NUREMBERG AND TOKYO}

\begin{abstract}
This article analize the experiences for the construction of international criminal justice which they built and added the main factors of competition serve basis today for the reality depicted in the International Criminal Court since the courts at Nuremberg and Tokyo. Through this paper is intended to show that before addressing the question of contemporary admissibility before the ICC, it is important to know as their bases have been built and where become its main institutions.
\end{abstract}

\footnotetext{
Docente e Investigador Facultad de Derecho Universidad Militar Nueva Granada Bogotá . Magíster en Derecho Penal. Universidad Santo Tomás Bogotá D.C., - Universidad de Salamanca, España. Especialista en Derecho Público de la Universidad Nacional de Colombia. Estudios de Posgrado en Derecho Constitucional Universidad de Salamanca, España. Abogado y Especialista en Derecho Penal Universidad Santo Tomás Bogotá. Profesor Visitante del Instituto Técnológico de Monterrey, México, dentro del programa Líderes Académicos. D.C. Producto de investigación: Proyecto-Admisibilidad de la CPI frente al Derecho Interno, aspectos sustanciales y procesales. E-Mail: jaime.sandoval@unimilitar.edu.co; jaisandoval@yahoo.com.
} 


\title{
Keywords:
}

International Jurisdiction, Trials of Nuremberg, of Tokyo; Crimes: Against peace; Against humanity; of war. Responsibility: of the Superior. Individual responsibility; responsibility by the organization.

\section{O DESENVOLVIMENTO DA CONCORRÊNCIA INTERNACIONAL. PRIMEIRAS CONTRIBUIÇÕES DESDE NUREMBERG E TÓQUIO}

\begin{abstract}
Resumo
Este artigo analisa as experiências para a construção de Justiça penal internacional que desde que tribunais de Nuremberg e Tóquio construídos e adicionados que os principais fatores de concorrência baseiam-se em apresentam a realidade retratada no Tribunal Penal Internacional. Através deste livro destina-se a mostrar que antes de abordar a questão da admissibilidade contemporânea antes do ICC, é importante saber como suas bases foram construídas e se tornam-se suas principais instituições.
\end{abstract}

\section{Palavras-chave}

Competência internacional, julgamentos de Nuremberg, de Tóquio; Crimes: contra a paz; Contra a humanidade; da guerra. Responsabilidade: do Superior. Responsabilidade individual; responsabilidade pela organização.

\section{INTRODUCCIÓN}

La competencia de la CPI en el plano Internacional obedece a la construcción progresiva superior a los 50 años de la Justicia Penal Internacional; ámbito que plantea nuevos desafíos para los Estados que presentan fenómenos de violencia a gran escala, que pudieran catalogarse en el contexto de los graves crímenes contra la humanidad y por ende son proclives a la intervención del organismo internacional.

Este nuevo plano de análisis que ejerce notable influencia en el derecho interno, se erige en la actualidad como el factor principal de preocupación de un sistema penal como el nacional, que desde la intervención de instancias internacionales en el marco de los derechos humanos, ha generado importantes consecuencias en el fuero interno. En la actualidad la competencia de la CPI ya no obedece a una esperanza como hace diez años, sino que constituye una realidad que se encuentra plasmada en los condicionamientos del Estatuto de Roma de 1998 y en sus instrumentos adicionales, como las reglas de procedimiento y prueba y los elementos del crimen.

Para los efectos previstos, se tiene como punto de partida la vigencia de la CPI en Colombia, la cual se produjo el $1^{\circ}$ de noviembre de 2002 frente a los crímenes de lesa humanidad y genocidio y el $1^{\circ}$ de noviembre de 2009 en virtud de la vigencia de los crímenes de guerra en el derecho interno, luego del vencimiento del término de 7 años descrito en el artículo 124 del ER, relativo a la cláusula transicional que Colombia adoptó en el momento del depósito de los instrumentos internacionales. En todo caso, es importante tener en cuenta que ello obedece al criterio establecido sobre la competencia suplementaria que los mismos instrumentos desarrollan en el orden interno 
y que constituyen el factor de admisibilidad, objeto principal de la presente investigación.

Sin embargo, antes de abordar esta problemática contemporánea, en el presente artículo, a través de un método hermenéutico y analítico, se emprenderá el análisis del contexto necesario para la presencia de dichos crímenes objeto de persecución internacional a partir de experiencias comparadas y antecedentes de otros tribunales internacionales, que le han precedido a la CPI y que han trazado el camino hacia la jurisdicción penal Contemporánea. En particular se analizarán las experiencias de Nüremberg y del Tribunal Internacional de Tokio, en donde precisamente se estructuraron los principales presupuestos de la justicia internacional actual, a través de una metodología que analiza fuentes directas como la sentencia, la acusación y los fallos de tales instancias, mediante el análisis histórico, comparado, de revisión, entre otras. Lo anterior a fin de determinar en esta primera parte uno de los factores de competencia, como el factor objetivo, de admisibilidad actual y que tuvo su origen en los tribunales de la posguerra en donde se adicionan aportes relevantes a la construcción de la justicia penal internacional.

\section{DESARROLLO DE LA COMPETENCIA INTERNACIONAL PREVIA A LA CPI. LOS TRIBUNALES ESPECIALES PREVIOS A LA SEGUNDA GUERRA MUNDIAL DEL SIGLO XX}

Los acontecimientos relativos a la responsabilidad personal por crímenes de connotación universal, no pueden identificarse antes del siglo XIX, bajo una vigencia plena de reglas de conducta de carácter penal, basadas en los derechos humanos o en el derecho humanitario para infractores individuales, ni menos aún, tribunales y procedimientos internacionales establecidos para tal efecto, tan sólo pueden mencionarse actos juzgados por diversas jurisdicciones, como el caso del caballero francés Jean de Melun, tomado prisionero por un caballero inglés de nombre Henri
Poinfroit en 1359 (Córdoba Triviño J. 2001. PP. 37- 38). Entre ellos se acordó el pago de una suma de dinero por su rescate. Inicialmente, parte de la suma fue pagada por Melun, sin embargo, luego de su liberación, él mismo se negó a pagar el dinero restante. Posteriormente, luego de un arbitraje fallido, Poinfroit acudió ante el Tribunal de Maréchaux para reclamar su derecho que inicialmente le fue concedido y posteriormente negado por el parlamento de Paris ${ }^{1}$. La Corte constituida en tal virtud, decidió que la promesa de Melun era invalida y ordenó a Poinfroint a que reembolsara la suma recibida, que pagara una multa y que llevara a cabo una erectio armorum, donde quiera que la subversio hubiere tenido lugar. 9 (Córdoba Triviño J. 2001. PP.37 - 38).

De igual forma puede citarse el caso de Peter Von Hagenbach, juzgado y condenado por las atrocidades cometidas al asediar la ciudad de Breischach (Alto Rhin), para someterla al poder de Borgoña. En el proceso se estableció que un representante del Archiduque que actuaba como demandante, declaró que von Hagenbach había "pisoteado las leyes de Dios y del hombre". Al acusado se le formulaban cargos por homicidio, violación, perjurio y otros, entre los que se incluía, impartir órdenes a sus mercenarios no germanos de matar a los hombres en las casas donde se alojaran para que las mujeres y los niños quedaran a su merced (Greppi E. 1999). El argumento de la defensa, basado esencialmente en la carta del acatamiento de órdenes superiores, sostenía que " Sir Peter Von Hagenbach no reconoce otro juez, ni señor diferente al Duque de Borgoña ", cuyas órdenes no podía cuestionar. " ¿No se sabe acaso que los soldados deben absoluta obediencia a sus superiores? ". Esta consideración básica fue subrayada por el hecho que el Duque

1 El parlamento de París apoyó la negativa de Melun a pagar, pues la nota carecía del sello real y además, el peticionario sostuvo que había sido cautivo durante una tregua en la cual todos los actos de guerra eran prohibidos. Por otra parte, según el jus armorum de la época Poinfroint, no podía adquirir sus propios prisioneros (Córdoba Triviño J. 2001 PP.37 y 38). 
había confirmado y ratificado personalmente, ex post factum que " todo se había hecho en su nombre" 2 . Este juicio fue realizado por un tribunal que conformaron varios jueces procedentes de diferentes Estados y principados de Europa en 1474 (Córdoba Triviño J. P. 39).

Posteriormente, a raíz de los hechos originados en la Batalla de solferino del 24 de junio de 1859 , se origina el movimiento que dio origen a la Cruz Roja Internacional (1863) a instancias de Gustav Moynier y Henri Dunant (Hernández Hoyos D. 2002. P. 37.), que permitió sentar las bases para una posible jurisdicción internacional. Precisamente en virtud de la creación del comité de Ginebra, que suscribió en 1864 el convenio denominado "Convenio de Ginebra de 22 de agosto de 1864", destinado a aliviar la suerte de militares heridos por los ejércitos en campaña, se originó la iniciativa de crear un Tribunal Internacional que se encargara de juzgar la comisión de los crímenes de guerra. A este tribunal se someterían, en caso de guerra entre dos o más potencias contratantes, las demandas por las infracciones a dicho convenio. ${ }^{3}$

2 En el proceso. Von Hagenbach solicitó un aplazamiento para pedirle al Duque que confirmara sus argumentos, pero el tribunal se negó a concedérselo por considerar la solicitud contraria a las leyes de Dios y porque los crímenes cometidos por el acusado ya habían quedado plenamente establecidos. Así pues, el tribunal halló culpable al acusado y von Hagenbach, privado de su grado de caballero y de los privilegios que éste le otorgaba (por haber cometido crímenes que tenía la obligación de prevenir), fue ejecutado tras la orden: “ Que se haga justicia " impartida por el alguacil. GREPPI E. 1999. Disponible en: http://www.icrc.org/spa/resources/ documents/misc/5tdnnf.htm. Consultada el 7.03.2012.

3 El tribunal estaría conformado por cinco árbitros, tres nombrados por las potencias signatarias del Convenio. Convocadas previamente por el Presidente de la Confederación Suiza y uno que representaba a cada Estado Beligerante. En el caso de que la contienda se desarrollara en más de un Estado soberano, aquellos que hicieran causa común nombrarían un solo árbitro. La iniciativa no fue aceptada debido a la crítica de los académicos. (Hernández Hoyos D. 2002. P. 37).
En el mismo sentido, en los Estados Unidos, los primeros Artículos de guerra fueron promulgados en 1775 y contenían previsiones específicas para la sanción de los oficiales que no lograran mantener el "buen orden" entre las tropas. Este mandato fue mantenido y reforzado en los artículos de guerra de 1806 y sirvió de fundamento para la persecución de las infracciones del derecho de las Naciones. La regulación más destacada en este campo fue el Código Lieber de los Estados Unidos de 1863, expedido con motivo de la Guerra Civil de Secesión, el cual se da como el primer intento de codificación de las leyes de la guerra por iniciativa del Presidente Abraham Lincoln (Bassiouni M. CH. 1984 P. 59). En el artículo 44 del Código de Lieber, proferido el 24 de abril de 1863 y cuyo verdadero título era: Instrucciones para la conducción de los Ejércitos de los Estados Unidos en Campaña, se estipula la sanción de todo acto de violencia desaforada cometido contra personas en el país invadido. (Sandoval Mesa J. A. 2003. P. 31.). Así mismo, se castigan la destrucción de la propiedad y las conductas de robo, pillaje o saqueo, la violación, las lesiones personales y la mutilación o el asesinato de las personas que no toman parte en el conflicto, es decir, lo que hoy se entiende como población civil. ${ }^{4}$

De otra parte, al parecer, a fines del siglo XIX, "los tribunales británicos en la guerra con los Boers, procesaron a algunos prisioneros por los crímenes de guerra cometidos antes de ser detenidos ${ }^{5}$.

4 Bajo la vigencia del Código de Lieber los Estados Unidos juzgaron y condenaron a muerte al Mayor confederado HENRY WIRZ, comandante de un campo de prisioneros de guerra, por su intervención en la muerte de varios miles de prisioneros de la Unión en la prisión de Andersonville. El tribunal que lo juzgó por los crímenes de guerra cometidos lo halló culpable pese a su alegato de haber actuado en obedecimiento a órdenes superiores. (Córdoba Triviño J. 2001, PP. 43, 44 y 45; Bassiouni M. CH. 1984, P. 61.)

5 En forma individual, los Estados Unidos también constituyeron tribunales de Crímenes de Guerra, tras la guerra hispano-americana y la ocupación de Filipinas en 1902. (Bassiouni M. CH. 1984. P. 61). 
Sin embargo, no hay ninguna evidencia de clara conciencia en la necesidad de juzgar a los responsables de los atentados de lesa humanidad cometidos en las diversas confrontaciones que se dieron durante este tiempo, en los comienzos del siglo XX (Córdoba Triviño J, 2001, p. 45).

Por otro lado, algunas Constituciones como la de Weimar de 1919, reconocían el principio de responsabilidad individual por violación a las leyes de la guerra, en particular las contenidas en la Convención de La Haya de 1907 (Córdoba, 2001, p. 46). Sobre estos instrumentos, Prieto Sanjuán señala que resulta curioso que a pesar de estos esfuerzos, en el siglo XX se recibiera el activo de la Primera Conferencia de Paz de la Haya (1899) y se hubiere reforzado con una segunda (1907). El mundo se embarca en un término similar, no en una conferencia, sino en la Primera Guerra Mundial, conocida como la Gran Guerra. El fin de esta primera confrontación europea, donde además intervendrán los Estados Unidos, termina con la respuesta de las potencias Aliadas y Asociadas a las observaciones de la delegación alemana sobre las condiciones de paz (Conditions de paix-Conditions of peace), mejor conocida como el Tratado de Versalles de 1919 (Prieto, 2005, p. 21).

En virtud del Tratado mencionado (Versalles de 1919), se estableció una verdadera cláusula de juzgamiento ante tribunales militares por actos con violación a las leyes y costumbres de guerra de connotación internacional. Se impuso en este sentido, una responsabilidad directa en virtud de los hechos que comprometieron en la primera Guerra Mundial al Kaiser Guillermo II. En dicho tratado se impusieron además a Alemania: cláusulas territoriales, como la restitución de la Alsacia-Lorena a Francia, o militares, como la reducción de armamentos y efectivos ${ }^{6}$. La importancia de este Tribunal radica en el

6 También puede citarse la desmilitarización de la rivera izquierda del Rhin, la supervisión de una comisión de control Interaliada y en fin, de carácter económico con la obligación de pagar los perjuicios sufridos por los aliados. (Prieto, 2005, p. 21). establecimiento del principio de punibilidad por crímenes de guerra, así como la autorización a los aliados de la creación de tribunales nacionales para juzgar tales crímenes, (art. 229) así como la creación de un cuerpo especial para informar sobre las personas que debían ser perseguidas. ${ }^{7}$

Así mismo, por primera vez se formulaba el crimen de Agresión, evento que fundaba la acusación del mandatario alemán, dado que dicha conducta implicaba la vulneración del orden internacional, sin embargo, la insuficiente cooperación de los Estados hizo difícil que este tipo de tribunales tuviera éxito. El fracaso del Tribunal internacional que se había previsto para el juzgamiento del Kaiser, se debió a la negativa del gobierno de Holanda de entregarlo en extradición, lo que a su vez impidió el inicio de los posibles juicios que tendrían lugar en otros países ${ }^{8}$, por las sucesivas negativas de extradición desde Alemania, de los demás oficiales nacionales comprometidos en el asunto (Córdoba, 2001, p. 46).

Esta serie de motivos condujo a las potencias aliadas a ceder, para que los tribunales nacionales se encargaran del juzgamiento de los alemanes, lo cual debía llevarse a cabo ante la Corte de Leipzing. El armisticio Alemán fue firmado el 11

7 La Comisión tenía como función ser un órgano decisorio de las responsabilidades de los autores de la guerra, para la aplicación de las sanciones mediante el informe de 3 de febrero de 1920. En él los aliados pusieron en conocimiento de Alemania, los nombres de 896 pretendidos criminales de guerra, aunque por razones políticas la lista se redujo a 45 y de estos, Alemania tan sólo juzgó a 12 ante el Tribunal Supremo del Reich, (Leipzing) resultando absueltos seis. No se aplicó el art. 228 porque Alemania se negó a la Extradición de sus Nacionales. (Bassiouni ,1984, p. 61).

8 En el mismo sentido, Es importante resaltar que en Leipzing, no sólo fue identificado un único Estado como responsable, sino además y por primera vez un individuo, el Ex Emperador Guillermo II por su "Suprema Ofensa contra la moralidad internacional y la santidad (carácter sacro) de los Tratados", previendo la posibilidad de juzgarlo por un Tribunal Internacional conformado por representantes de las potencias aliadas, pese a la negativa de los Países Bajos de conceder su extradición. (Prieto, 2005, p. 22.) 
de noviembre de 1918, pero sólo hasta el 23 de mayo de 1921 se dio inicio a los juicios. Paralelo a ellos, se desarrolló un movimiento de opinión pública en Alemania a favor de los procesados, pues éstos no eran vistos como criminales de guerra, sino como verdaderos héroes que estaban siendo subyugados y perseguidos por las potencias vencedoras. Esta serie de sucesos dio al traste con las aspiraciones de LEIPZING, autoridad que en realidad nunca llegó a operar, pero de todas maneras impuso el principio según el cual, deben ser llevados a juicio todos aquellos que violan las leyes y costumbres de la guerra amparados en el hecho de cumplir con un deber hacia su país (Córdoba, 2001, p. 47).

A pesar de este intento frustrado de justicia internacional, se señala la capacidad criminal del individuo en el plano internacional, pues se abre la posibilidad de imputar ciertas violaciones graves de obligaciones internacionales a las personas naturales o físicas, en la medida en que ciertas normas convencionales o consuetudinarias le son exigibles. En este sentido, se previó que a las demás personas comprometidas en la violación de Leyes y usos de la guerra terrestre, pudieran ser juzgadas por la jurisdicción militar de cada una de las potencias aliadas (Prieto, 2005, p. 22).

Además de acuerdo con Prieto Sanjuán, este instrumento tejido en una época en que el paredón, la horca o la decapitación, sin previo juicio, eran la regla respecto de quienes resultaban vencidos en la guerra, adicionaba el reconocimiento de ser juzgado por un Tribunal Especial. Aspecto que podría ser visto como un avance importante en materia penal, dada la constitución de un órgano jurisdiccional internacional, que de paso va a limitar el voluntarismo y descentralización de los Estados, para concebir bienes o intereses comunes en la sociedad (Prieto, 2005, p. 22).

Posteriormente, en el período entre guerras se presentó cierta paralización de los esfuerzos por regular este tipo de actos y conductas internacionales, aspecto que se comenzó a dilucidar durante la segunda Guerra Mundial (Bassiouni, 1984, p. 61). Sin duda, estos antecedentes sirvieron de base para el establecimiento del aporte más representativo desde la declaración de derechos humanos de 1948, en la creación de una competencia universal encargada de juzgar aquellas conductas ejercidas en contra de la humanidad y del paso lento pero seguro de la consolidación del Estatuto Penal de Roma, no sin antes pasar a examinar los contextos exigidos, después de la segunda guerra mundial en los denominados juicios de Nüremberg.

\section{ELEMENTOS DE LA COMPETENCIA Y ACTUACIONES EN EL TRIBUNAL MILITAR INTERNACIONAL EN NÜREMBERG}

Como es frecuente en este tipo de jurisdicciones, los sucesos y el contexto determinan el fenómeno posterior que desemboca en crisis y violencia a gran escala, que después debe ser reprimida por la comunidad internacional. En este caso, el motivo que dio lugar al Tribunal de Nüremberg, fue propiciado, no por la preponderancia y hegemonía política en Europa, sino por un espíritu nacionalista concebido más bien, en la reivindicación intelectual de Alemania, que tenía por objeto fundar un régimen de mil años, separando a la especie humana en dos categorías irreconciliables, la raza aria y los sub-hombres (judíos y gitanos) que debían ser eliminados o esclavizados (Prieto, 2005, pp. 26 - 27).

Este suceso que trajo como consecuencia el holocausto de 6 millones de judíos, permitió que las potencias aliadas que finalmente lograron imponerse, se interrogaran respecto al qué hacer con los autores de tales hechos (Prieto, 2005, p. 27), situación que en la Segunda Posguerra, desde el punto de vista penal implicaba resolver, si existía la posibilidad de construir tipos penales que afectaran a la persona individual, sin la mediación del derecho estatal y si existía un principio de responsabilidad jurídico penal directo del individuo ante el derecho internacional. En segundo término, se trataba de establecer que las normas de derecho internacional, contaran con un principio preferencial obligatorio que estuviera 
más allá del derecho Estatal, en orden a prevenir no sólo la acción penal de los individuos, sino de los Estados. Finalmente, cómo asumir los supuestos jurídicos del llamado Acto de Estado, dado que los hechos punibles contra el derecho penal internacional pudieran ser castigados superando los límites de esta justificante (Ambos y Guerrero, 1999, p. 53).

Sin oposición, con el establecimiento de los Tribunales Ad-hoc, para el juzgamiento de los crímenes de la posguerra en Nüremberg y Tokio, así como sus precedentes de la década de los noventa, constituidos por los Tribunales Ad-hoc para la antigua Yugoslavia y Ruanda, se dio respuesta a las dificultades planteadas, pero sobre todo en materia de jurisdicción internacional, sin embargo, las mismas observaron diversas características que finalmente moldearon el instrumento permanente de la Corte Penal Internacional. Todo este amplio panorama surgió de los episodios que rodearon los juicios de Nüremberg, conforme con los siguientes presupuestos.

En efecto, las potencias adoptan inicialmente la Declaración de Saint James (Reino Unido) en 1942 y al año siguiente la declaración de Moscú, firmada en 1943 (Prieto, 2005, p. 28). Las cuatro potencias aliadas finalmente coincidieron en el establecimiento de un Tribunal Internacional especial para juzgar a los criminales de Guerra Nazis. Sin embargo, el temor giraba en torno al procedimiento ejercitado y se permitiera la justificación de los actos ejecutados por los eventualmente acusados, situación que desembocó en el acuerdo para la persecución y castigo de los grandes criminales de guerra del eje europeo, traducido en "La Carta de Londres de 8 de agosto de 1945" que creó el Tribunal de Nüremberg (Bassiouni, 1984, p. 62). A este documento se la adaptó un Protocolo rectificativo de aquel y un cuarto documento contentivo de las reglas de procedimiento adoptado el 29 de octubre de 1945 (Prieto, 2005, p. 28). Además de estos dos tribunales militares internacionales, los aliados crearon Tribunales Militares en sus zonas de ocupación respectivas, mediante la ordenanza 10 del Consejo de Control del 20 de diciembre de $1945^{9}$, permitiendo a cada potencia ocupante juzgar a oficiales alemanes de bajo rango (Bassouni, 1984, p. 62).

El Tribunal de Nüremberg, se enfrentó principalmente a las diferencias de sistemas legales entre las potencias aliadas pues, los británicos y norteamericanos se basaban en el common law, Francia se fundaba en el derecho civil, y la Unión Soviética tenía su propia justicia socialista. El Acuerdo mencionado (Londres, 8 de agosto de 1945), permitió un consenso entre los partícipes y se desarrolló un proceso mixto, expresado en la declaración que contenía el anexo del estatuto del nuevo Tribunal referido anteriormente (Corte Constitucional Colombiana, Sentencia C-578, 2002, p. 31).

Bajo este desenvolvimiento de sucesos y pese al calificativo de justicia de vencedores, se debe destacar que el Tribunal también fue el resultado de un siglo de reflexión, originado como se analizó en el punto anterior, en antecedentes previos como los juicios de Leipzing (entre 1919 y 1922) y más atrás en documentos como la declaración de París, adoptada en la guerra de Crimea de 1856, así como en el denominado Código Lieber de 1863, en el Convenio de Ginebra de 1864, las Convenciones de la Haya de 1899 y 1907, instrumentos que fueron imputados y oponibles a la responsabilidad de Alemania. También le sería

9 Antes, durante y después de los juicios de Nüremberg, los Estados Unidos condenaron a 1814 personas en su zona de ocupación, de los cuales 450 fueron ajusticiados. Gran Bretaña condenó a 1085 y 240 ajusticiados, Francia a 2107 y 109 ajusticiados y la URSS alrededor de 10.000 sin conocerse el número de ajusticiados. El número total de actuaciones judiciales adicionales por parte de las potencias aliadas según se infiere del informe de la Comisión de Crímenes de Guerra de las Naciones Unidas fue: Estados Unidos, 809; Gran Bretaña 524; Australia 256; Francia 254; Países Bajos 30; Polonia 24; Noruega 9; Canadá 4; China 1. En Nüremberg fueron enjuiciados 19 personas y el único juicio fuera de Alemania fue el de Eichmann, caso Juzgado por el Estado de Israel sobre la base de la teoría de la competencia universal en crímenes internacionales. Esta teoría fue fundamentalmente la mantenida en los procesos de Nüremberg en relación con los crímenes contra la humanidad. (Bassiouni, 1984, pp. 62 - 63). 
imputada en Nüremberg, el incumplimiento al pacto de la Sociedad de Naciones que prohibía la guerra de agresión, el Protocolo de 1924, los Acuerdos de Locarno de 1925 y sobre todo, el Pacto de Briand-Kellog de 1927 cuya prohibición sobre el uso de la fuerza, había sido aceptada por Alemania mediante declaración con Polonia en 1934. (Prieto, 2005, p. 28).

Si se observa, más allá de las críticas al Tribunal, eran indiscutibles las violaciones a las normas internacionales relatadas, las cuales constituían el orden establecido hasta entonces para la defensa de intereses universalmente reconocidos por la comunidad de naciones de ese tiempo. Así mismo, la justicia internacional desde sus antecedentes más relevantes como Nüremberg, previó los consensos entre diferentes sistemas jurídicos, precedente que permanece en la interpretación de las cláusulas actuales del Estatuto de Roma de 1998 (arts. 17, 58).

\section{RESPONSABILIDAD EN NÜREMBERG, APORTES NECESARIOS PARA LA ADMISIBILIDAD CONTEMPORÁNEA}

Por otra parte, a través de las decisiones del Tribunal de Nüremberg, se designaron como personas responsables de crímenes internacionales, en primer lugar, a las naturales autoras de los crímenes, a los dirigentes, organizadores, provocadores o cómplices, partícipes en la elaboración o en la ejecución de un plan, a fin de cometer uno de los crímenes de competencia del Tribunal.

La calidad de gobernante o el hecho de haber cumplido órdenes de un superior jerárquico, no constituían hechos que justificaran los crímenes definidos por el Acuerdo de Londres. El tribunal internacional tenía una competencia limitada al castigo de los principales responsables, pues los ejecutantes, miembros de la SS, de la Gestapo, del cuerpo de jefes nazis y del SD (el servicio de seguridad de Himmler) debían ser juzgados por los tribunales nacionales, tal y como fue ejecutado (Prieto, 2005, p. 31). Así, en el primer volumen de procedimientos del Tribunal de Nüremberg, en el apéndice A de la acusación, se realiza la declaración individual de responsabilidad mediante declaraciones a nombre de cada acusado individual, que constituyeron los cargos en los que se basó la acusación, según el Principio VI (artículo $6^{\circ}$ ) del Estatuto del Tribunal. Por ejemplo, en el caso de Goering se señalaron los cargos ocupados, funciones y regencias en el tercer Reich entre 1932 y 1945, para analizar el contexto de su actuación, respecto de los cuatro crímenes por los cuales fue juzgado. ${ }^{10}$ Este tipo o método de análisis del contexto que rodea las conductas, ha trascendido en la actualidad y frente a cada situación objeto de examen ante tribunales internacionales, implica su revisión para determinar el alcance de los crímenes internacionales que se investigan, sobre todo para conocer las políticas de los regímenes infractores, si fueron anteriores, concomitantes o posteriores a la comisión de los delitos. En muchos casos

10 Nuremberg Trial Proceedings vol. 1 Apéndice A: Declaración de responsabilidad individual por crímenes establecidos en los Cargos Primero, Segundo, Tercero y Cuarto: Goering: El acusado Goering entre 1932 y 1945 fue: Miembro del Partido Nazi, Líder Supremo del ministerio SA, General de la SS, miembro y presidente del Reichstag, del Interior de Prusia, Jefe de la Policía Secreta de Prusia y Policía del Estado, Jefe del Consejo de Estado de Prusia, Custodio del Plan de Cuatro Años, Ministro del Reich, Comandante en Jefe de la Fuerza Aérea, Presidente del Consejo de Ministros para la Defensa del Reich, miembro del Consejo Secreto de Gabinete, jefe Industrial de la cosechadora y el Sucesor Designado a Hitler. El acusado Goering usó los cargos mencionados, su influencia personal, y su conexión estrecha con el Führer de tal forma que: promovió el acceso al poder de los conspiradores nazis y la consolidación de su control sobre Alemania, expuestos en el Primer Cargo de la Acusación; promovió la preparación militar y económica para la guerra expuestos en el Primer Cargo de la Acusación; participó en la planificación y preparación de la conspiración nazi para las Guerras de Agresión y Guerras en Violación de Tratados Internacionales, Acuerdos y Garantías expuestas en los los Cargos Primero y Dos de la Acusación. También autorizó, dirigió y participó en los Crímenes de Guerra expuestos en el Tercer Cargo de la Acusación y en los Crímenes contra la Humanidad expuestos en el Cuarto Cargo de la Acusación, incluyendo una amplia variedad de crímenes contra las personas y bienes. Traducción libre. Disponible en http://avalon.law.yale.edu/subject menus/20th.asp. Consultada el 2.04.2012. 
puede determinar la diferencia entre un delito ordinario y un crimen internacional.

Por otro lado, un aspecto relevante de la responsabilidad en el Tribunal de Nüremberg, lo constituyó la orientación que le otorgó el Fiscal Jackson, al señalar la idea de comisión de crímenes por un Estado o una corporación, como una ficción, pues estos siempre son cometidos por personas; sin embargo y en su criterio, era apropiado emplear la ficción de la responsabilidad estatal o corporativa para imponer una responsabilidad colectiva, pues este tipo de legalismo no podía convertirse en peana para la impunidad personal ${ }^{11}$. En este sentido se reconoce un indicio de los crímenes cometidos a nombre de una organización, interpretación relevante en la jurisdicción penal internacional. Sobre este punto, en el primer volumen de procedimientos del Tribunal de Nüremberg, en el Apéndice B de la acusación, se realiza la declaración de grupos y organizaciones, señalando el nombre de cada uno de ellos, de acuerdo con el establecimiento de la criminalidad o según el caso, que deberían ser declarados criminales. En el texto analizado se cita el Die Reichsregierung (Gabinete del Reich); al Das Korps Der Politischen Leiter Der Deutschen Arbeiterpartei Nationalsozialistischen (Liderazgo del Partido Nazi), entre otras organizaciones a las cuales se les adscribieron las responsabilidades correspondientes ${ }^{12}$.

11 En tal sentido, en el Tribunal tanto personas físicas como las organizaciones criminales vinculadas al régimen Nazi fueron objeto de punición y para asegurar el equilibrio procesal, se garantizò la libertad de palabra, el sistema acusatorio, la defensa en propia causa etc., en donde los veinte volúmenes de los debates reproducidos dan cuenta del análisis minucioso con el cual fueron analizadas las pruebas, adelantados los interrogatorios y escuchada la defensa. (Prieto, 2005, p. 29)

12 En la acusación del Tribunal de Nüremberg, aparecen los siguientes fragmentos respecto de la responsabilidad colectiva, en los siguientes términos: Apéndice BStatement of criminality of Groups and Organizations Declaración de la delincuencia de grupos y organizaciones The statements hereinafter set forth, following the name of each group or organization named in the Indictment as one which should be declared criminal, constitute matters upon which the prosecution will rely inter alia as establishing the criminality of the group or organization: Las declaraciones indicadas a continuación, siguiendo el nombre de cada grupo u organización nombrada en la acusación como uno que deberían ser declarados criminales, constituyen cuestiones en las que la acusación se basará, entre otras cosas con el establecimiento de la criminalidad del grupo u organización: DIE REICHSREGIERUNG (REICH CABINET) Die Reichsregierung (Gabinete del Reich):"Die Reichsregierung (Reich Cabinet)" referred to in the Indictment consists of persons who were: "Die Reichsregierung (Gabinete del Reich)" mencionado en la acusación que se compone de personas que corresponden a: (i) Members of the ordinary cabinet after 30 January 1933, the date on which Hitler became Chancellor of the German Republic. I) Los miembros del gabinete ordinario después del 30 de enero de 1933, la fecha en que Hitler es nombrado canciller de la República Alemana. The term "ordinary cabinet" as used herein means the Reich Ministers, ie, heads of departments of the central Government; Reich Ministers without portfolio; State Ministers acting as Reich Ministers; and other officials entitled to take part in meetings of this cabinet. El término "gabinete ordinario", como se usa aquí significa que los Ministros del Reich, es decir, los jefes de departamentos del Gobierno central; Ministros del Reich sin cartera, Ministros de Estado actuando como Ministros del Reich, y otros funcionarios con derecho a participar en las reuniones de este gabinete..." DAS KORPSDERPOLITISCHENLEITER DER NATIONALSOZIALISTISCHEN DEUTSCHEN ARBEITERPARTEI (LEADERSHIP CORPS OF THE NAZI PARTY) Das Korps Der Politischen Leiter Der Deutschen Arbeiterpartei Nationalsozialistischen (Liderazgo del Partido Nazi) "Des Korps der Politischen Leiter der Nationalsozialistischen Deutschen Arbeiterpartei (Leadership Corps of the Nazi Party)" referred to in the Indictment consists of persons who were at any time, according to common Nazi terminology, "Politischen Leiter" (Political Leaders) of any grade or rank. "Des Korps der Politischen Leiter der Deutschen Arbeiterpartei Nationalsozialistischen (Liderazgo del Partido Nazi)" mencionado en la acusación que se compone de personas que se encontraban en cualquier momento, de acuerdo a la terminología común nazi, "Politischen Leiter" (Líderes Políticos) de cualquier grado o rango.The Politischen Leiter comprised the leaders of the various functional offices of the Party (for example, the Reichsleitung, or Party Reich Directorate, and the Gauleitung, or Party Gau Directorate), as well as the territorial leaders of the Party (for example, the Gauleiter). El Politischen Leiter integrado por los líderes de las distintas dependencias funcionales de la Parte (por ejemplo, el Reichsleitung, o Partido del Reich Dirección y Gauleitung, o Partido Gau -Dirección), así como los líderes territoriales del partido (por ejemplo, el Gauleiter)..."

The prosecution expressly reserves the right to request, at any time before sentence is pronounced, that Politische Leiter of subordinate grades or ranks or of other types or classes, to be specified by the Prosecution, be excepted from further proceedings in this Case No. 1, but without prejudice to other proceedings or actions against them. La fiscalía se reserva expresamente el derecho de solicitar, en cualquier momento antes de dictarse sentencia, que 
En cuanto al procedimiento definido en el acuerdo referido, según la opinión del Juez Robert $\mathrm{H}$. Jackson, el mismo operaba en beneficio de los demandados. Estos podían, por ejemplo, pasar al estrado y testificar bajo juramento en su propia defensa o simplemente presentar al final del juicio un testimonio no juramentado ante la corte, sin someterse a interrogatorio (Bassiouni, 1999, p. 61).

De igual forma, Los redactores de las reglas del Tribunal de Nüremberg, luego de múltiples discusiones, definieron los crímenes como:

\section{Art. $6^{\circ}$ : a) Crímenes contra la paz; b) Crímenes de Guerra; c) Crímenes contra la humanidad ${ }^{13}$.}

Politische Leiter de grados o rangos subordinados o de otros tipos o clases, a especificar por la Fiscalía, sean excluidos de otros procedimientos en este caso $\mathrm{N}^{\circ} 1$, pero sin perjuicio de otros procedimientos o acciones en su contra. Traducción libre, Disponible en http://avalon. law.yale.edu/. Consultada el 2.04.2012

13 En la Sentencia General de 30 de Septiembre y $1^{\circ}$ de Octubre de 1946, el Tribunal de Nüremberg estableció lo siguiente con respecto al artículo $6^{\circ}$ : The individual defendants are under, which is as follows: Los acusados individuales están acusados en virtud del artículo 6 de la Carta, que es el siguiente:

"Article 6. The Tribunal established by the referred to in hereof for the trial and punishment of the major war criminals of the European Axis countries shall have the power to try and punish persons who, acting in the interests of the European Axis countries, whether as individuals or as members of organisations, committed any of the following crimes: "Artículo 6. El Tribunal establecido por el Acuerdo mencionado en el artículo 1 del presente para el enjuiciamiento y castigo de los criminales de guerra más importantes de los países europeos del Eje, tendrá la facultad de juzgar y sancionar a las personas que, actuando con los intereses del mismo, ya sea como individuos o como miembros de organizaciones, haya cometido alguno de los siguientes delitos:" The following acts, or any of them, are crimes, coming within the jurisdiction of the Tribunal for which there shall be individual responsibility: "Los siguientes actos, o cualquiera de ellos, son crímenes, que se incluyen en la jurisdicción del Tribunal y que darán lugar a responsabilidad individual: " (a) Crimes against Peace: namely, planning, preparation, initiation or waging of a war of aggression, or a war in violation of international treaties, agreements or assurances, or participation in a common plan or conspiracy for the accomplishment of any of the foregoing: "(A) Crímenes contra la Paz: a saber, la planificación, preparación, iniciación o ejecución de una guerra de agresión o una
Sobre este aspecto, los crímenes de guerra fueron fáciles de tipificar, debido a los antecedentes de derecho consuetudinario reconocidos por las partes, con la Convención de la Haya de

guerra en violación de tratados internacionales, acuerdos o garantías internacionales, o la participación en un plan común o conspiración para la perpetración de cualquiera de lo anterior:

" (b) War Crimes: namely, violations of the laws or customs of war. Such violations shall include, but not be limited to, murder ill-treatment or deportation to slave labour or for any other purpose of civilian population of or in occupied territory, murder or ill-treatment of prisoners of war or persons on the seas, killing of hostages, plunder of public or private property, wanton destruction of cities, towns or villages, or devastation not justified by military necessity: "(B) Crímenes de Guerra: Es decir, violaciónes de las leyes o costumbres de la guerra. Tales violaciones incluyen, pero no se limitan al asesinato, malos tratos o la deportación para realizar trabajos forzados o para cualquier otro propósito, sobre la población civil o en los territorios ocupados. El asesinato o los malos tratos a los prisioneros de guerra o personas en alta mar, el asesinato de rehenes, el saqueo de bienes públicos o privados, la destrucción arbitraria de ciudades, pueblos o aldeas, o la devastación no justificada por necesidades militares:

“(c) Crimes against Humanity: namely, murder, extermination, enslavement, deportation, and other inhumane acts committed against any civilian population, before or during the war, or persecutions on political, racial or religious grounds in execution of or in connection with any crime within the jurisdiction of the Tribunal, whether or not in violation of the domestic law of the country where perpetrated. "(C) Crímenes contra la Humanidad: a saber, el asesinato, el exterminio, la esclavización, la deportación y otros actos inhumanos cometidos contra cualquier población civil, antes o durante la guerra, o persecuciones por motivos políticos, raciales o religiosos en ejecución de o en conexión con cualquier crimen de la competencia del Tribunal, estén o no en violación del derecho interno del país donde hubieren sido perpetrados. "Leaders, organisers, instigators and accomplices participating in the formulation or execution of a common plan or conspiracy to commit any of the foregoing crimes are responsible for all acts performed by any persons in execution of such plan." "Los dirigentes, organizadores, instigadores y cómplices participantes en la formulación o ejecución de un plan común o conspiración para cometer cualquiera de los delitos mencionados son responsables de todos los actos realizados por cualquier persona en ejecución de dicho plan." These provisions are binding upon the Tribunal as the law to be applied to the case. Estas disposiciones son vinculantes para el Tribunal como la ley que debe aplicarse al caso. The Tribunal will later discuss them in more detail; but before doing so, it is necessary to review the facts. Sentencias Nüremberg. Traducción Libre. Disponible en: http://avalon.law.yale.edu/. Consultada el 2.04.2012. 
1907, además de las legislaciones de derecho pactadas en tratados (Bassiouni, 1999, p. 62). En aplicación a tal definición, en el volumen 1 de procedimientos del Tribunal de Nüremberg, se realizó la acusación por el cargo tercero, relativo a los crímenes de guerra (Artículo $6^{\circ}$ literal b), con respecto a todos los imputados, por los actos realizados mediante el concierto con otros y bajo la preparación de un plan común para perpetrar crímenes de tal naturaleza entre el $1^{\circ} \mathrm{de}$ Septiembre de 1939 y el 8 de mayo de $1945^{14}$.

Los crímenes contra la humanidad al no hacer parte de ningún tratado, resultaban más difíciles de tipificar, en opinión de Bassiouni y con el fin de evitar legislar ex post facto, se impuso una teoría de extensión jurisdiccional que consistía, en la interpretación de los crímenes de guerra, los cuales se aplicaban a ciertas personas protegidas, a saber, civiles durante tiempos de confrontación entre Estados Beligerantes (Bassiouni, 1999, p. 61). De esta forma, a las prescripciones contra la humanidad, se extendían las prescripciones de los comportamientos de guerra, para la misma categoría de personas protegidas dentro de un Estado en particular, siempre y cuando estos crímenes estuvieren relacionados con la iniciación y con la conducta de guerra agresiva, o con los crímenes de guerra (Bassiouni, 1999, p.61).

14 Nuremberg Trial Proceedings vol. 1 Acusación: Tercer Cargo - Los Crímenes de Guerra (Carta, el artículo 6 , en especial 6-b)-VIII. Exposición del Delito: Todos los acusados de crímenes de guerra entre el 1 de septiembre de 1939 y 08 de mayo 1945, en Alemania y en todos los países y territorios ocupados por las Fuerzas Armadas alemanas desde el 1 de septiembre de 1939, en Austria, Checoslovaquia e Italia, y en alta mar: Todos los acusados, actuando en concierto con otros, prepararon y ejecutaron un Plan Común o Conspiración para cometer Crímenes de Guerra como se define en el artículo 6 (b) de la Carta. Este plan implicaba, entre otras cosas, la práctica de la "guerra total", incluyendo los métodos de combate y ocupación militar en conflicto directo con las leyes y costumbres de la guerra; y la comisión de los delitos cometidos en el campo de batalla durante encuentros con ejércitos enemigos, en contra de los prisioneros de guerra y en territorios ocupados contra la población civil de esos territorios. Traducción libre. Disponible en: http://avalon.law.yale.edu/ subject menus/20th.asp. Consultada el 1.04.2012.
Sobre el particular, Prieto Sanjuán (2005, p. 28 ), coincide con Bassiouni al indicar que en definitiva estos crímenes de lesa humanidad presuponían un vínculo con la guerra y además, generaban la competencia del Tribunal que le permitió conocer y fallar su ocurrencia. Desafortunadamente, como resultado de esta interpretación, los crímenes cometidos antes de 1939, no fueron procesados (Bassiouni, 1999, p. 63). En este sentido, Kai Ambos (2004, p. 276) anota que en definitiva, pudo haberse afectado el principio de no retroactividad de la ley penal, pues en el Tribunal de Nüremberg, el principio de interés de justicia prevaleció y de alguna manera, sí se permitió la legislación ex post facto de los hechos, sobre todo, dada la amplitud de las consideraciones bajo las cuales fue concebido (Ambos, 2004, pp. 276 - 278).

Frente a este último aspecto, en la decisión de acusación realizada el 6 de octubre de 1945, se estableció que la regla de los crímenes contra la humanidad pretendía reprimir las vulneraciones de tratados internacionales e incluso de los principios generales del derecho, acto que se corrobora en el primer volumen de procedimientos del Tribunal de Nüremberg, en el cargo cuatro de la acusación, que indica el plan común para cometer entre otros los crímenes de asesinato y persecución de todos los que fueron o eran sospechosos de ser hostiles al partido nazi, en particular los representantes de la nación judía ${ }^{15}$. Uno de los aspectos más relevantes lo

15 Nuremberg Trial Proceedings vol. 1 - Acusación: Cargo Cuarto. (Carta, Articulo 6, en especial 6-c). X. Declaración del delito. Todos los acusados cometieron Crímenes contra la Humanidad durante un período de años anteriores al 8 de mayo de 1945 en Alemania y en todos los países y territorios ocupados por las fuerzas armadas alemanas desde el 1 de septiembre de 1939, en Austria y Checoslovaquia, en Italia y en alta mar. Todos los acusados, actuando en concierto con otros, prepararon y ejecutaron un plan común o conspiración para cometer crímenes contra la humanidad tal como se define en el artículo 6 (c) de la Carta. Este plan implicaba, entre otras cosas, el asesinato y la persecución de todos los que fueron o que eran sospechosos de ser hostiles al Partido Nazi y todos los que estaban o se hicieron sospechosos de oponerse al plan común alegado en el Cargo. Los crímenes contra la humanidad, fueron 
constituye la interpretación en la acusación, de elementos que en la actualidad constituyen ingredientes necesarios para la configuración de los delitos de lesa humanidad, que pese a sus antecedentes de comienzos del siglo XX, de manera concretan se reprimen en Nüremberg. En las actuaciones del Tribunal, tanto en la acusación como en la sentencia, además de relacionar la conducta descrita en el Estatuto (Principio VI-C o Artículo 6 c), se señalan métodos y crímenes que constituyeron violaciones de los convenios internacionales, de leyes penales internas y de los principios generales del derecho penal según se derive de la legislación penal de todas las naciones civilizadas. Lo anterior representó en primer lugar, la indicación de las normas vulneradas y el alcance internacional de la conducta y en segundo término, la participación y el patrón sistemático de la conducta, el cual se conoce en

cometidos por los acusados y por otras personas de cuyos actos son responsables (en el artículo 6 de la Carta), como las demás personas, al cometer los Crímenes de Guerra, realizaron sus actos en la ejecución de un plan común y conspiración para cometer los crímenes de guerra. También, en la formulación y ejecución del plan y conspiración en los que todos los acusados participaron como líderes, organizadores, instigadores y cómplices. Estos métodos y crímenes constituyeron violaciónes de los convenios internacionales, de leyes penales internas, de los principios generales del derecho penal según se derivan de la legislación penal de todas las naciones civilizadas y participaron en y parte de un patrón sistemático de conducta. Estos actos eran contrarios al artículo 6 de la Carta. La Fiscalía se basan en los hechos expuestos en el Tercer Cargo también constituyen crímenes contra la humanidad..." En particular se detallan en el texto de la acusación, las atrocidades contra los judíos frente a conductas como "...(A) Asesinato, exterminio, esclavitud, deportación y otros actos inhumanos cometidos contra población civil antes y Durante la guerra; (B) persecución por motivos políticos, raciales y religiosos en ejecución del plan y en relación con el plan común descrito en el primer cargo. Responsabilidad Individual y colectiva...", suscrita por: / S / Robert H. Jackson. Actuando en nombre de los Estados Unidos de América. / S / François de Menthon. Actuando en nombre de la República Francesa. ts / Hartley Shawcross. Actuando en nombre del Reino Unido de Gran Bretaña e Irlanda del Norte. / S / R. Rudenko. Actuando en nombre de la Unión de Repúblicas Socialistas Soviéticas. Traducción Libre. Disponible en http://avalon.law.yale.edu/subject menus/20th.asp. Consultada el 1.04.2012 la actualidad en el Estatuto de Roma de 1998, como la política sistemática y generalizada de los crímenes de lesa humanidad (Art. $7^{\circ}$ ).

Finalmente, la acusación por los "crímenes contra la paz", no tenía un precedente legal, salvo el episodio Kaiser de Alemania al finalizar la primera guerra mundial. El obstáculo fue superado en el artículo $6^{\circ}$ de la Carta de Londres, al disponer la acusación de aquellos que dirigieron o participaron en la guerra de agresión contra otras naciones, violando los tratados y los principios del Derecho Internacional. Todo ello, sin contar con el precedente del pacto Brian-Kellog de 1927, sobre la prohibición del uso de la fuerza, solemnizado con Polonia en 1934 y referido anteriormente.

Esta fue la mejor base a la cual pudieron acudir los aliados. El aspecto más rescatable de este suceso, se presentó con la propuesta de la Unión Soviética, quienes pretendían incluir dentro del artículo, la frase que indicaba la especificidad de la conducta, en cuanto a "los países del eje Europeo", posición que contrastó con los señalamientos de los Estados Unidos. Según el parecer norteamericano, tal razonamiento no era viable debido a la prohibición que en este sentido se regulaba en su Constitución. Además, de acuerdo con las palabras del Juez Jackson, la prohibición contra la agresión es Universal y podía operar incluso en contra de su país, fundamento que desde entonces, impuso el Crimen de Agresión a los ojos del Derecho Internacional. (Bassiouni, 1999, p.63).

Según Carolina S. Anello (2003. p. 22) en este aspecto de definición de los crímenes motivo de la competencia radica una de las críticas al Tribunal de Nüremberg, pues con respecto a los crímenes mencionados como ya se indicó anteriormente, en relación con los crímenes contra la humanidad, no existían propiamente leyes penales internacionales anteriores a la comisión del delito. Todo ello significaba la vulneración de principios como el de legalidad, irretroactividad de la ley penal, juez natural, falta de tipicidad debido a la Imprecisión del concepto y contenido de los crímenes contra la guerra, la humanidad y contra la paz. 
No obstante tales aseveraciones, lo cierto es que además de los instrumentos comentados anteriormente, la Organización de las Naciones Unidas legitimó los principios aplicados por el Tribunal y mediante resolución 95 (I), de 11 de diciembre de 1946, confirmó los principios de derecho internacional reconocidos por el Estatuto y por las sentencias del Tribunal de Nüremberg. Tales principios fueron formulados por la Comisión de Derecho Internacional a pedido de la Asamblea General a través de la resolución 177-II (Anello, 2003, p. 22). El documento consta de VII principios que sintetiza lo principales aportes del Estatuto de Nüremberg (acuerdo cuatripartito de Londres 8 de agosto de 1945).

Ahora bien, siguiendo el presente análisis, en el artículo $8^{\circ}$ del acuerdo de Londres, se removió la excepción del deber de obediencia, convirtiéndola en una circunstancia atenuante; sin embargo, en algunos casos concretos, el Tribunal dejó de aplicar tales prescripciones permitiendo la Defensa cuando el subordinado no tenía una alternativa moral para rehusarse a ejecutar la orden ${ }^{16}$. Para avanzar en las tareas del Tribunal, se organizaron equipos de investigación por parte de los cuatro países principales, tarea facilitada por la ocupación militar norteamericana en territorio alemán, lo cual permitía el acceso a la mayoría de documentos y testigos civiles (Bassioni, 1999, p. 65).

El Tribunal Militar Internacional en Nuremberg, acusó a 24 personas, de las cuales 22 fueron procesadas. Tres demandados fueron absueltos, 12 fueron sentenciados a muerte (colgados), tres fueron sentenciados a cadena perpetua y el resto fueron sentenciados a condenas de prisión que oscilaban entre 10 y 20 años. Hermann Goering se suicidó al final del juicio. Todos los demandados eran alemanes y ningún otro miembro del personal

16 Toda esta serie de situaciones, una vez resueltas, sirvieron de cuerpo normativo al establecimiento del Tribunal para que finalmente, la Carta de Londres fuera anexada al Acuerdo, el 8 de Agosto de 1945. El documento fue firmado en principio por las cuatro potencias aliadas $y$ después se le sumaron diecinueve Estados. (Bassiouni M. CH. Vol 10. Mayo de 1999 P. 65) militar Aliado fue procesado por Crímenes de guerra contra los alemanes.

Para dar un ejemplo sobre el contenido de la acusación, la responsabilidad tanto individual como de la organización entre otros aspectos comentados anteriormente, la siguiente transcripción revela el alcance de la imputación realizada:

“...Acusación formal - Tribunal Militar Internacional, Los Estados Unidos de America, los Franceses República, el Reino Unido de Gran Bretaña e Irlanda del Norte, y la Unión de Repúblicas Socialistas.

-en contra-

Hermann Wilhelm Goering, Rudolf Hess, Joachim Von Ribbentrop, Robert Ley, Wilhelm Keitel, KaltenbrunnerErnst, Alfred Rosenberg, Hans Frank, Frick Wilhelm, Streicher Julius, Walter Funk, Hjalmar Schacht, Gustav Krupp von Bohlen und Halbach, KARL Doenitz, Erich Raeder, Baldur von Schirach, Sauckel Fritz, Alfred Jodl, Martin Bormann, Franz von Papen, Arthur Seyss-Inquart, Albert Speer, Constantin von Neurath y Hans Fritzsche, individualmente y como miembros de cualquiera de los siguientes grupos $u$ organizaciones a las que respectivamente Perteneció, a saber: Die Reichs Regierung (Gabinete del Reich); Das Korps Der Politischen Leiter der Deutschen Arbeiterpartei Nationalsozialistischen (Liderazgo del Partido Nazi); Die Schutzstaffeln der Deutschen Nationalsozialistischen Arbeiterpartei (conocida comúnmente como la "SS") y que incluye DER Sicherheitsdienst ( comúnmente conocida como la "SD"); DIE Geheime Staatspolizei (Policía Secreta del Estado, comúnmente conocida como la "Gestapo"); Die Sturm Abteilungen der NSDAP (comúnmente conocido como el "SA"), y el Estado Mayor y Alto Mando de la fuerzas armadas alemanas, según se definen en el Apéndice B, 
Los acusados.

I. Los Estados Unidos de América, la República Francesa, el Reino Unido de Gran Bretaña e Irlanda del Norte, y la Unión de Repúblicas Socialistas Soviéticas por el abajo firmante, Robert H. Jackson, Francois de Menthon, Hartley Shawcross y RA Rudenko, debidamente designado para representar a sus respectivos gobiernos en la investigación de los cargos en su contra y el enjuiciamiento de los principales criminales de guerra, de conformidad con el Acuerdo de Londres de fecha 08 de agosto 1945, y la Carta de este Tribunal que le acompaña; acusan, en los aspectos que en adelante se establece, de Crímenes contra la Paz, Crímenes de Guerra y Crímenes contra la Humanidad, y de un Plan Común o Conspiración para cometer esos delitos, según se definen en la Carta del Tribunal, $y$ por consiguiente consideran acusados en esta causa y procesados por los cargos que figuran a continuación: Hermann Wilhelm Goering, Rudolf Hess, Joachim von Ribbentrop, Robert Ley, Wilhelm Keitel, Kaltenbrunner Ernst, Alfred Rosenberg, Hans Frank, Frick Wilhelm, Streicher Julius, Walter Funk, Hjalmar Schacht, Gustav Krupp von Bohlen Und Halbach, Karl Doenitz, Raeder Erich, Baldurvon Schirach, Sauckel Fritz, Alfred Jodl, Martin Bormann, Franz von Papen, Arthur Seyss-Inquart, Albert Speer, Constantin von Neurath y Hans Fritzsche, individualmente y como miembros de alguno de los grupos $u$ organizaciones nombradas a continuación.

II A continuación se nombran como grupos u organizaciones (ya disuelto), que deberían ser declarados criminales por razón de sus objetivos y los medios utilizados para la realización del mismo y en relación con la condena de los acusados como de los nombrados, ya que los miembros de los mismos: Die Reichsregierung (Gabinete del Reich); Das Korps Der Politischen
Leiter der Deutschen Arbeiterpartei Nationalsozialistischen (Liderazgo del Partido Nazi); Die Schutzstaffeln der Deutschen Nationalsozialistischen Arbeiterpartei (conocida comúnmente como la "SS") y que incluye Der Sicherheitsdienst (conocida comúnmente como la SD “"); DIE Geheime Staatspolizei (Policía Secreta del Estado, comúnmente conocida como la" Gestapo "); Die Sturmabteilungen der NSDAP (comúnmente conocido como el" $S A$ "), y el Estado Mayor General del Alto Mando de las Fuerzas Armadas Alemanas.

La identidad y la pertenencia a los grupos $u$ organizaciones mencionadas en los títulos anteriores son en lo sucesivo en el Apéndice B se define más en particular- 6 de octubre de 1945..."17

Estos procesos, pese a que fueron justos para los acusados, iban en una sola dirección (Bassiouni, 1999, p. 65). Sobre este punto denominado justicia de vencedores, como aspecto final de la controversia, pese a las críticas anotadas, es de advertir que se trataba de un contexto que jugaba con unas reglas diversas a las actuales y desde esa perspectiva se puede explicar este concepto anotado por Bassiouni.

Además, se trataba de un período que había producido un corte en la historia, en donde el mundo anterior debía reconstruirse con los elementos de su tiempo. Sobre el particular, como lo afirmó Gustav Radbruch en aquel entonces, en el antecedente de la sentencia de Nüremberg se adicionaron dos nuevos pensamientos al derecho internacional establecido (2009, p.18). De una parte, las obligaciones de derecho internacional no deben ligar a los Estados, sino obligar a los gobernantes y a cada ciudadano en particular; de otra, en el futuro, la violación de las obligaciones de derecho internacional deben ser penadas en la persona del culpable, conforme a un nuevo

17 Disponible en http://avalon.law.yale.edu/subject_menus/ judcont.asp, Consultada el 28.03.2012 
derecho penal internacional establecido por la jurisprudencia (Radbruch, 2009, p. 18). De todas formas Radbruch manifestó que el Tribunal constituía una semilla para el futuro, toda vez que no podía aseverarse su validez real, debido a que sólo se aplicó a los alemanes vencidos, sin que se pudiese extender a otros gobernantes y que un Tribunal para que fuera supranacional, debía ser constituido por representantes supranacionales también, aun por encima de su propia nación (2009, p. 18). Al final en su pensamiento, pese a sus observaciones, se nota partidario y conforme con el fallo y condenas impuestas a la cúpula nazi, toda vez que en su criterio se trató de un caso de maldad extrema que en criterios de Kant, significa actuar contra la ley moral (Radbruch, 2009, pp. 19 - 20) con todas las consecuencias que incluso se reflejan, en la cita que realiza de un amigo de él, quien fuera objeto de torturas en el campo de concentración de Buchenwald.

En todo caso es de entender que el tribunal surge en este momento histórico, en donde también se originan las naciones unidas, fruto de la posguerra, como organismo aglutinador que puede a partir de allí y desde el punto de vista ideológico, regir los destinos del mundo vertido en las experiencias desastrosas de la guerra, para trazar nuevas líneas de pensamiento en materia penal para reprimir los casos de la $2^{\text {a }}$ guerra mundial. Desde luego en esta medida, no todos los responsables en general de la guerra como lo anota Radbruch, fueron juzgados, sino únicamente los protagonistas de la agresión. Sin embargo, a pesar del señalamiento anotado también es cierto que sin tales antecedentes no habría sido posible construir estos criterios de justicia internacional, con unas propias reglas y admisibilidad de tipo mixto que cobran vigencia hasta la actualidad.

De igual forma, también es viable citar como desarrollo posterior a Nüremberg, en la posguerra, en relación con la Ley $\mathrm{N}^{\circ} 10$ del Consejo de Control Aliado, que respecto de los crímenes de lesa humanidad, se produjeron efectos que permanecen hasta hoy, como los de dejar de exigir una conexión con crímenes de guerra o crímenes contra la paz, como la prevista en el Estatuto del Tribunal Militar Internacional. ${ }^{18}$

El avance en la formulación protección y adecuación de esta serie de conductas, que también aparece reflejada en el Estatuto de Roma, permiten establecer en este antecedente de jurisdicción internacional, límites tanto de la normalidad como de la confrontación. Entre los numerosos procesos penales nacionales cabe destacar doce procesos que fueron llevados a cabo ante tribunales militares estadounidenses después del Juicio de Nuremberg, hasta mediados de 1949 (Nürnberger Nachfolgeprozesse), en adelante denominados procesos sucesivos al juicio de Nuremberg. Cada uno de los doce procesos se concentraba en un grupo de autores. Fueron acusados representantes de la profesión médica, de la Administración de Justicia, de las fuerzas armadas, de la economía y de la industria, así como dirigentes del Estado y del Partido Nacionalsocialista (Werle, 2005, pp. 57 - 59).

Finalmente, en adición a la resolución 95 (I) de 11 de diciembre de 1946, la Asamblea General de las Naciones Unidas dio instrucciones a la Comisión de Derecho Internacional, órgano codificador en estas materias, para que tratara la cuestión de los delitos contra la paz, la seguridad de la humanidad y se iniciaran los trabajos conducentes a la creación de una Corte Penal Internacional de Carácter Permanente, sin embargo, este proyecto solamente tendría una versión definitiva en 1996 para que la actual CPI tuviera su origen en 1998 (Prieto, 2005, p. 31). La Presentación en 1950 de la definición de los Principios de Derecho Internacional reconocidos por el Estatuto y las sentencias del Tribunal de Nüremberg", pueden considerarse como válidos para la era actual (Prieto, 2005, p. 31). Sin duda este es el principal aporte del Tribunal de Nüremberg, toda vez que constituye el fundamento de competencia

18 La ley $\mathrm{N}^{\circ} 10$ se refería al Castigo de Personas que fueran culpables de haber cometido Crímenes de guerra, Crímenes contra la Paz o Crímenes contra la Humanidad de 20 de diciembre de 1945 (WERLE G. 2005 PP. 57, 58 y 59.) 
material objeto de definición de los crímenes a nivel internacional, que hacen parte de las instancias actuales encargadas de su juzgamiento y represión.

\section{LA COMISIÓN PARA EL LEJANO ORIENTE Y EL TRIBUNAL MILITAR INTERNACIONAL DE TOKIO.}

La Comisión para el Lejano Oriente (Far Eastern Commission - FEC) se acordó en Moscú en diciembre de 1945, y algunos elementos sobre el Control del futuro del Japón, fueron asignados a la URSS. Los Estados Unidos tuvieron a su cargo la dirección de la Comisión, la cual se conformaba por once Estados, de los cuales, las cuatro potencias aliadas tenían poder de veto. La funciones de la Comisión (FEC), se dirigían a definir una política de ocupación para el Japón y coordinar las políticas aliadas en el lejano oriente; orientar el sistema común de investigación y acusación de sospechosos por crímenes de guerra; diseño de los juicios y procedimientos, ejecución de sentencias, así como liberación de procesados, entre otras. Según la opinión de Bassiouni "La Comisión para el Lejano Oriente se convirtió en poco más que una sociedad en la que se debatía, y cuando finalmente se firmó un tratado de paz con Japón sufrió una muerte silenciosa. (1999, p. 68).

Por su parte, el 19 de enero de 1946, el General MacArthur, supremo comandante de las potencias aliadas (SCAP) dispuso en nombre de la comisión para el Lejano Oriente, instaurar un Tribunal Especial para Juzgar los Crímenes de Guerra del Ejército Japonés. A este Tribunal se le criticó la ausencia de imparcialidad y las discutidas decisiones, todas ellas influenciadas por el General Norteamericano. El tribunal tendría a cargo, juzgar a las personas responsables denominados criminales de clase A, por crímenes contra la paz, la clase $\mathrm{B}$ para los crímenes de guerra y la clase $\mathrm{C}$ para los crímenes contra la humanidad, tal y como se desarrolló en Nüremberg (Prieto, 2005, p. 30).

El 13 de abril de 1946 la Comisión para el Lejano Oriente emitió una decisión acerca de su política respecto a la "Aprehensión, juicio y castigo de los criminales de guerra. En el artículo $6^{\circ}$ de la decisión, se autorizaban facultades al General MacArthur, para establecer una Agencia especial que actuara bajo su mando para investigar los informes de crímenes de guerra, recoger y analizar pruebas, así como organizar la captura de sospechosos. Este artículo, le otorgaba al General, la facultad de poder decidir, que individuos u organizaciones serían acusados y ante que Corte debían presentarse (Bassiouni, Vol 10. Mayo de 1999 P. 68).

Finalmente, el Tribunal de Tokio fue presidido por el australiano William Webb quien fue encargado del enjuiciamiento de 28 ex dirigentes políticos y militares, de los cuales 25 fueron efectivamente juzgados, dos murieron en el transcurso del proceso y uno fue internado por problemas mentales. A partir del 3 de mayo de 1946 hasta el 12 de noviembre de 1948, siete de ellos fueron condenados a la pena capital, dieciséis a cadena perpetua, uno a veinte y otro a siete años de prisión. En todo caso, a los condenados a pena capital se les aplicó la sentencia al mes siguiente (Prieto, 2005, p. 31).

Los participantes de la Comisión, así como los miembros del Tribunal, eran escogidos como representantes de cada país y no como miembros de una organización de juzgamiento, situación que originó la politización de los juicios instaurados, irregularidades en los procedimientos y abusos de discrecionalidad judicial. Los demandados al ser escogidos sobre la base del criterio político generalmente se enfrentaban a un juicio injusto ${ }^{19}$.

En 1949, la Comisión emitió una recomendación formal a las diecinueve potencias aliadas en el Lejano Oriente, según la cual, los procesos japoneses por crímenes de guerra debían llevarse a cabo a más tardar el 30 de septiembre

19 Estos acontecimientos eran reveladores, en la medida en que además de que ninguno de los aliados fue procesado por crímenes de guerra, "la ejecución de las sentencias era inconsistente y manejada por los caprichos del General MacArthur, quien tenía el poder de otorgar indultos, reducirlas y otorgar la libertad condicional a criminales de guerra convictos. (Bassiouni, 1999, p. 71) 
de 1949. Posteriormente, el tratado de paz con el Japón, firmado en San Francisco el 8 de septiembre de 1951 por 48 Estados, disponía en su artículo II que todos los criminales de guerra hallados culpables debían ser trasladados al Japón para cumplir el resto de su sentencia bajo la Dirección de la omisión. Lo anterior tenía como propósito efectuar liberaciones tempranas y así, entre 1951 y 1957, se les otorgó la libertad provisional o se les conmutó la pena a todos los criminales de guerra convictos del Lejano Oriente (Bassiouni, 1999, p. 71).

A diferencia de lo que sucedía en Alemania, donde aquellos acusados y declarados culpables de cometer crímenes de guerra, se convertían en su mayoría en parias de su sociedad, los Japoneses no consideraban a tales personas criminales sino víctimas, los juicios según su parecer eran una venganza de los victoriosos, expresada en términos de la Justicia de los Victoriosos". Además, el tinte político de los procesos del Lejano Oriente, se expresó con mayor plenitud, "en el juicio, condena y ejecución del General Tomoyuki Yamashita, adelantado en las Filipinas. El mismo fue guiado por el interés personal del General MacArthur, quien ordenó el juicio en su contra, a pesar de que el General Japonés no había ordenado ni conocido de ningún crimen de guerra (Bassiouni, 1999, p. 74). La imparcialidad como se puede observar, no fue la constante en los tribunales que por segunda oportunidad comprometían la responsabilidad internacional de un Estado.

Así mismo, se criticó la política norteamericana de entonces, sobre el archipiélago de Japón, puesto que en criterio de Prieto Sanjuán, el Emperador Hiroito como parte de la campaña en Asia, nunca fue formalmente acusado, pues el mismo contaba con el apoyo del General Mac Arthur, quien no deseaba desestabilizar el país tocando uno de los símbolos de dicho país, así mismo, tampoco se juzgaron otros responsables como los miembros de la Unidad 731 entre otros, tal vez observando desde el punto de vista de Estados Unidos, el papel y la visión futura que después tendrá Japón en la guerra fría (2005, p. 30 y 31).
A pesar de las críticas mencionadas, el aporte relevante del Tribunal Militar Internacional de Tokio, corresponde al denominado Estándar Yamashita, determinado en su condena, pues si bien el mismo no había ordenado ningún crimen y en su mayoría tales delitos fueron cometidos por sus subordinados, en el proceso se determinó su responsabilidad como superior jerárquico por no haber adoptado las medidas tendientes a evitar un gran número de atrocidades contra la población civil. Además de ello, las medidas debían adoptarse toda vez que ostentaba la calidad de Comandante General de la Armada 14 del Ejército Imperial Japonés y Gobernador Militar de las Islas Filipinas desde finales de 1944 hasta 1945 (Aponte A. 2011, PP. 213 Y 214).

En este asunto, si bien la defensa apeló la decisión, alegando que el General Yamashita no participó directamente en la comisión de los crímenes y que ello vulneraba la Convención de Viena y la Constitución Política de Norteamérica, la Corte Suprema de los Estados Unidos desestimó la apelación y confirmó la decisión de condena al imputado (Aponte, 2011, pp. 213 - 214).

El sentido del fallo determinó que según la Convención de la haya de 1907, en su anexo cuarto, artículos $1^{\circ}$ y 43 , se establece la existencia de un superior jerárquico en organismos beligerantes encargados de la responsabilidad por las acciones de los subalternos, en consecuencia, les asiste a dichos superiores, los deberes de vigilancia y supervisión, facultad que le impone al comandante tomar todas las medidas que estén en su poder para restaurar y asegurar el orden público, la seguridad y que se respeten las leyes que rigen en el país. Por lo tanto, las leyes de la guerra presuponen que las violaciones de las mismas, han de ser evitadas mediante el control de las operaciones de guerra por parte de los comandantes, quienes son responsables hasta cierto punto por sus subordinados (Aponte, 2011, pp. 214 - 215).

En todo caso pese a las críticas y a los límites que posteriormente se han fijado a nivel jurisprudencial a este tipo de responsabilidad del superior jerárquico, es una previsión internacional que 
ha subsistido los diferentes cambios evolutivos y hoy aparece consagrada en el artículos 28 y 33 del Estatuto de Roma de 1998, con las diferencias de interpretación, que en la era actual deben ser atendidas, más si después del denominado estándar Yamashita, fueron aprobados los 4 Convenios de Ginebra de 1949 con sus dos protocolos adicionales y demás normativa actual, tanto en materia de DIH como del Derecho Internacional de los Derechos Humanos.

\section{CONCLUSIONES}

En general los desarrollos iniciales de la competencia para juzgar crímenes internacionales, han servido de base en los últimos 50 años, para que el Estado permanezca atento a regular los ámbitos de anormalidad y de alteración de la convivencia pacífica. Incluso, esta connotación se vio reflejada en la Convención de las Naciones Unidas, sobre la imprescriptibilidad de los crímenes de guerra y de los crímenes de lesa humanidad de 26 de noviembre de 1968 (Entrada en vigor. 11.11.1970 - Colombia no la ha ratificado-), que en su artículo $1^{\circ}$ señala el alcance de estos dos tipos de conductas y su vez, genera otro precedente necesario para el establecimiento de una jurisdicción internacional (Compilación de Instrumentos Internacionales, 2002).

Así mismo, los precedentes originados en la competencia de Nüremberg, han permitido por ejemplo la creación del crimen de Genocidio, mediante la Convención de 1948, el desarrollo de los crímenes objeto de represión, así como los procedimientos y demás aspectos que posteriormente han sido consagrados en el Estatuto del Tribunal penal Internacional para la Ex-Yugoeslavia (Res. UN. 827 de 25 de mayo de 1993). Dicho tribunal será objeto de estudio más adelante, en un artículo específico que analizará los precedentes de admisibilidad originados en los Tribunales ad hoc contemporáneos. Allí es preciso mencionar a los crímenes referidos anteriormente, como las previsiones del Art. $2^{\circ}$. Relativas a las Infracciones Graves de la Convención de Ginebra 1949; Art. $3^{\circ}$ Violaciones de las leyes o prácticas de guerra. Art. $4^{\circ}$ Genocidio. Art. $5^{\circ}$ Crímenes Contra la Humanidad, etc. (Valencia Villa, 2003).

De igual forma, de los precedentes analizados en el presente estudio se han desarrollado las conductas generadoras de la competencia universal, también referenciadas en instrumentos como el Estatuto del Tribunal Penal Internacional para Rwanda (Valencia Villa, 2003), establecido mediante Resol. 955 de 8 de noviembre de 1994, mediante la cual se describieron las conductas de Genocidio (Art. $2^{\circ}$ ); Crímenes de Lesa Humanidad (Art. $3^{\circ}$ ); Violaciones del art. $3^{\circ}$ Común de los Convenios de Ginebra y del Protocolo II (Art. $4^{\circ}$ ).

Ahora bien a partir de las definiciones que tienen lugar en Nüremberg, se han desarrollado otros instrumentos base de la competencia internacional, como la Convención contra la Tortura y otros tratos o penas crueles, inhumanos o degradantes de 10 de diciembre de 1984, cuya vigencia para Colombia se produce el 8.01.1988., junto con el desarrollo del delito Genocidio en el código penal, mediante la ley 589 de 2000 (Compilación de Instrumentos Internacionales, 2002).

Finalmente, no es posible desconocer al aporte relevante del Tribunal de Tokio relativo a la responsabilidad del superior jerárquico en materia penal internacional y al control de las operaciones de guerra que éste debe adoptar, siempre en protección de la población civil, toda vez que la omisión y actuaciones de los subordinados, pueden implicar la imputación penal ante los Tribunales Internacionales contemporáneos. Este factor también es decisivo en la competencia internacional que necesariamente debe buscar, no sólo a los ejecutores materiales, sino también como ocurrió en Nüremberg y Tokio, a los responsables de la organización. Más adelante se ampliarán estos conceptos en otro documento que se ocupará de la justicia internacional en la actualidad.

Por último, es importante destacar que en estos primeros tribunales se desarrollaron aspectos fundamentales para la competencia internacional, como el Factor Material, representado en la naturaleza de los crímenes, tipologías y situaciones en 
concreto que se deben analizar ante estas instancias; el factor Subjetivo referido a la nacionalidad y competencias de los posibles investigados; así como al factor Territorial, sustentado en el lugar donde se cometieron los crímenes. En este primer acercamiento, no se observan elementos de interés de justicia, salvo la descripción en Nüremberg de los delitos contra la Humanidad; o situaciones de impunidad, colapso judicial o interés de sustraer al imputado de la acción de la justicia. Todavía las condiciones y el contexto en que se analizaron los procesos de la segunda guerra mundial, no tuvieron el elemento histórico y jurídico comparable con las situaciones referenciadas, sin embargo los Tribunales analizados sirvieron de base para determinar el ámbito material de persecución de los crímenes más graves contra la humanidad.

\section{BIBILIOGRAFIA}

Ambos, Kai. (2004). El nuevo Derecho Penal Internacional. Lecturas compiladas. Curso Andino sobre la Corte Penal Internacional. Lima Perú febrero 2008.

Ambos, Kai y Guerrero, Oscar Julián. (1999). El Estatuto Penal de Roma, Primera Edición. Edit. Universidad Externado de Colombia, Bogotá D.C. Colombia.

Anello Carolina Susana. (2003). Corte Penal Internacional. Editorial Universidad. Buenos Aires, Argentina.

Aponte Cardona, Alejandro. (2011). Persecución Penal de Crímenes Internacionales. Diálogo Abierto entre la Tradición Nacional y el Desarrollo Internacional. Grupo Editorial Ibáñez, Pontificia Universidad Javeriana, Fundación Alemana Konrad Adenauer Stiftung. Bogotá D.C. Colombia.

Bassiouni M., Cherif. (Mayo de 1999.) De Versalles a Ruanda en 75 años: la necesidad de establecer una Corte Penal Internacional Permanente, (Volumen 10), Revista de Derecho Público, Universidad de los Andes. Bogotá D.C. Colombia.
Bassiouni M., Cherif. (1984.) Derecho Penal Internacional. Proyecto de Código Penal Internacional. Traducción, Notas y Anexo de DE LA CUESTA ARZAMENDI JOSE L. Editorial Tecnos S.A. Madrid, España

Cordoba Triviño, Jaime. (2001). Derecho Penal Internacional. Estudio de los delitos de Genocidio, de Lesa Humanidad y de los Crímenes de Guerra con referencia al nuevo Código Penal Colombiano. Ediciones Jurídicas Gustavo Ibáñez LTDA. Bogotá D.C. Colombia.

Corte Constitucional Colombiana. (30 de julio, 2002). Sentencia C-578. Magistrado Ponente. Dr. Manuel José Cepeda.

Edoardo Greppi, (1999) La evolución de la Responsabilidad Penal Individual bajo el Derecho Internacional, Revista de la Cruz Roja No 835. Ginebra: Comité Internacional de la Cruz Roja.

Hernández Hoyos, Diana. (2002). Lecciones de Derecho Internacional Humanitario. DIH. Segunda Edición. Ediciones Nueva Jurídica. Bogotá D.C., Colombia http://www.icrc.org/ spa/resources/documents/misc/5tdnnf.htm. Consultada el 7.03.2012.

Nuremberg Trial Proceedings. Vol. 1 - Acusación: Cargo Cuarto. (Carta, Articulo 6 , en especial 6-c). X. Declaración del delito. Crímenes contra la Humanidad Traducción Libre. Disponible en http://avalon.law.yale.edu/subject menus/20th. asp. Consultada el 1.04.2012

Nuremberg Trial Proceedings. (6 de Octubre, 1945). Acusación Formal, Tribunal Militar Internacional de 6 de octubre de 1945. Disponible en http://avalon.law.yale.edu/subject menus/ judcont.asp, Consultada el 28.03.2012.

Nuremberg Trial Proceedings. (1946). Sentencia General de 30 de Septiembre y $1^{\circ}$ de Octubre de 1946. Sentencias Nüremberg. Traducción Libre. Disponible en: http://avalon.law.yale.edu/. Consultada el 2.04.2012. 
Nuremberg Trial Proceedings. (1945). Vol. 1 Acusación de 6 de octubre de 1945: Tercer Cargo - Los Crímenes de Guerra (Carta, el artículo 6, en especial 6-b)-VIII. Traducción libre. Disponible en: http://avalon.law.yale.edu/subject menus/20th. asp. Consultada el 1.04.2012.

Nuremberg Trial Proceedings. Vol. 1 Apéndice A: Declaración de responsabilidad individual por crímenes establecidos en los Cargos Primero, Segundo, Tercero y Cuarto: Goering. Traducción libre. Disponible en http://avalon.law.yale.edu/ subject menus/20th.asp. Consultada el 2.04.2012.

Nuremberg Trial Proceedings. Vol. 1. Acusación del Tribunal de Nüremberg, de 6 de octubre de 1945, respecto de la responsabilidad colectiva: Apéndice B Declaración de la delincuencia de grupos y organizaciones. Traducción libre, Disponible en http://avalon.law.yale.edu/. Consultada el 2.04.2012

Naciones Unidas. (2002).. Compilación de Instrumentos Internacionales. Derecho Internacional de los Derechos Humanos. Derecho Internacional Humanitario y Derecho Penal Internacional. Oficina En Colombia del Alto Comisionado de Las Naciones Unidas Para Los
Derechos Humanos. Tercera Edición, Bogotá D.C., Tercera Edición.

Prieto Sanjuán, Rafael A. (2005). La Internacionalización de la Jurisdicción Penal. De Versalles a Bagdad. Editorial Biblioteca Jurídica DIKE. Primera Edición. Bogotá

Radbruch, Gustav. (2009). Relativismo y Derecho. Trabajos traducidos entre 1934 y 1945. Serie Monografías. Editorial Temis. Segunda Edición. Traducción de Luis Villar Borda. Bogotá D.C. Colombia.

Sandoval Mesa, Jaime Alberto. (2003). La Incorporación de la Corte Penal Internacional. Análisis frente a la legislación Colombiana. Ediciones Nueva Jurídica. Primera Edición, Bogotá Colombia D.C.

Valencia Villa, Alejandro. (2003), Compilación de Derecho Penal Internacional. Oficina del Alto Comisionado para las Naciones Unidas. Bogotá D.C.

Werle, Gerhard. (2005). Tratado de Derecho Penal Internacional. Traducción María del Mar Díaz Pita y otros. Ed. Tirant Lo blanch. Valencia España. 


\title{
INTERPRETACIÓN E INTEGRACIÓN NORMATIVA
}

\section{Eleonora del Pilar Salazar Londoño*}

Fecha de recibido: 30 de septiembre de 2011

Fecha de aprobación: 12 de junio de 2012

Artículo resultado de reflexión

... dijeron incluso que la ley cuando nace es igual para todos y que la democracia es incompatible con tratos de favor.

José Saramago*

\begin{abstract}
Resumen
El objetivo del presente artículo es reflexionar sobre el fenómeno de la interpretación en la norma jurídica. Por esta razón, se construye un diálogo con diversos horizontes teóricos que se sitúan entre los teóricos del derecho de un pensamiento iuspositivista e iusnaturalista, dentro de teorías constructivistas, como Dworkin y Hart, teoría argumentativa como Alexy y Habermas, positivistas puros como Kelsen, entre otros. Todos alimentan el discurso hermenéutico con nuevos conceptos de interpretación, como nuevas tendencias de interpretaciones jurídicas. El diálogo entre los teóricos se direcciona a través de preguntas para resolver el problema de la interpretación en el tema de los principios y la integración normativa.
\end{abstract}

\section{Palabras Clave}

Integración normativa, Principios, Argumentación, Interpretación, Hermenéutica

\section{INTERPRETATION AND INTEGRATION NORMATIVE}

\begin{abstract}
Abstrac
The aim of this paper is to reflect on the phenomenon of interpretation in the rule of law. For this reason, to construct a dialogue with various theoretical horizons are among the legal theorists of natural law and legal positivist thinking within constructivist theories such as Dworkin and Hart, argumentative theory as Alexy and Habermas, pure positivists as Kelsen, between other. All feed hermeneutic discourse with new concepts of interpretation, as new trends in legal interpretations. The dialogue between theorists is routed through questions to solve the problem of interpretation on the issue of integrating the principles and rules.
\end{abstract}

* Licenciada en Filosofía y Letras de la Universidad Santo Tomás de Aquino. Especialista en Investigación y pedagogía Universidad Gran Colombia, especialista en Seguridad Social Universitaria Agustiniana. Actualmente cursa cuarto semestre en la Maestría Filosofía del Derecho y Teoría Jurídica en la Universidad Libre de Colombia. Profesor-investigadora de la Universidad Católica de Colombia

** Está expresión es tomada del libro Ensayo sobre la ceguera de José Saramago.(p.168). Premio Nobel de Literatura 1998 